\title{
Effect of Membrane Properties on Performance of Membrane Distillation for Ammonia Removal
}

\author{
Zongli Xie \\ CSIRO Materials Science and Engineering, Private Bag 33, Clayton South, Vic.3169, Australia \\ E-mail: zongli.xie@csiro.au \\ Manh Hoang, Tuan Duong, Derrick Ng \\ CSIRO Materials Science and Engineering, Private Bag 33, Clayton South, Vic.3169, Australia
}

Puyam Singh, Paramita Ray, A. V. R. Reddy, K. Parashuram \& S. Maurya

C.S.M.C.R.I. (CSIR) G.B. Marg, Bhavnagar 36400, India

$\begin{array}{lr}\text { Received: August 3, } 2011 & \text { Accepted: August 23, 2011 Published: January 1, } 2012 \\ \text { doi:10.5539/jmsr.v1n1p37 } & \text { URL: http://dx.doi.org/10.5539/jmsr.v1n1p37 }\end{array}$

\begin{abstract}
Membrane distillation (MD) has received much attention in recent years as an alternative technology for the removal of volatile compounds from industrial waters. The microporous hydrophobic membrane utilised in MD allows only vapour passing through and the process selectivity is essentially determined by the liquid-vapour equilibrium conditions existing at the liquid-membrane interface. In this study, a series of asymmetrically structured polyvinylidene fluoride (PVDF) hollow fibre membranes were fabricated and tested for the removal of ammonia from simulated industrial wastewater. The asymmetric membranes contain very thin skin layer with macrovoids supported underneath. Hollow fibre MD modules with membrane area of $0.06 \mathrm{~m}^{2}$ have been assembled and tested for dilute aqueous solutions containing ammonia at concentrations $<1000 \mathrm{mg} / \mathrm{L}$. The membranes were characterised in terms of porosity, thickness, hydrophobicity, water permeability, surface roughness and zeta potential. Sweep gas MD configuration was employed for all experiments and $>90 \%$ ammonia removal could be achieved. The results from the MD experiments were compared and the effect of membranes characteristics was discussed.
\end{abstract}

Keywords: Asymmetric hollow fibre, Membrane distillation, Ammonia removal, PVDF

\section{Introduction}

Membrane distillation (MD) is a thermal process driven by the vapor pressure difference of volatile components between the two surfaces of a non-wetted hydrophobic membrane. The hydrophobic nature of the membrane prevents penetration of the aqueous solution into the pores, resulting in a vapour-liquid interface at the pore entrance (Bougeecha, et al., 2002). Among various MD configurations, sweep gas MD combines a relatively low conductive heat loss of direct contact MD with a reduced mass transfer resistance of air gap MD. The principal advantage of sweep gas MD against other MD configurations arises from the fact that vapour molecules are carried away by the inert sweep gas and the condensation takes place outside the membrane module (El-Bourawi, et al., 2006). MD module, especially hollow fiber compared to flat sheet, is becoming more favourable as it has larger interfacial area per unit volume but more compact in size, thus requires a much smaller plant foot print.

In recent years, sweep gas MD has received increasing attentions in removing volatile compounds from aqueous streams (Qin et al., 1996; Semmens, et al., 1990; Tan, et al., 2006; Zhu et al., 2005). This is especially beneficial for recycling industrial wastewater containing low level of volatiles. However, there are no commercial membranes available for MD application to date and symmetric microfiltration hydrophobic membranes were used in most recent studies. Some common polymers which could be used as the MD membrane materials include polypropylene (PP), polytetrafluoro ethylene (PTFE), and polyvinylidene fluoride (PVDF) (Mulder, M., 
1996). PVDF is known to have advantages of good thermal and chemical resistance properties. In addition, unlike PP and PTFE which are limited by its symmetrical structures, PVDF has the extra advantage of forming asymmetric membranes (Tan, et al., 2006). Asymmetric membrane structure is known to have lower mass transfer resistances (Kong et al., 2000; Li et al., 2000).

In our previous work (Xie, et al., 2009), we have demonstrated potential application of sweep gas MD for removing ammonia from industrial wastewater by using commercial PTFE membrane. The objective of this study is to fabricate asymmetric hollow fibre PVDF membranes under various synthetic conditions and test their performance for removing ammonia from simulated industrial wastewater by sweep gas MD. Fabricated hollow fibre membrane were characterised via a range of techniques including optical microscope, AFM, contact angle and zeta potential with the aim to gain better understanding the relationship between membrane properties and MD performances.

\section{Experimental}

\subsection{Membrane synthesis and characterisation}

Polyvinyledenefluoride (PVDF) (SOLEF 1015/1001) from Solvay Advanced Polymers (USA), polyvinylpyrrolidone (PVP) (MW 40KDa) and ethylene glycol (EG) from National chemicals (India), polyethylene oxide (PEO) (MW 100KDa) from Aldrich (Germany), N,N-dimethylformamide (DMF) and N-methylpyrollidone (NMP) from Qualigen Fine chemicals (India) were used as received.

A mixture of PVDF $(12 \%, w / w)$ and EG $(8 \%, w / w)$ was dissolved in NMP under constant stirring at a temperature of $80^{\circ} \mathrm{C}$ to prepare a transparent spinning dope. The spinning dope was extruded under nitrogen environment through a double orifice spinneret. The water flowed through the inner nozzle of the spinneret acts as bore former by causing the phase inversion in the inner part of the PVDF hollow fibre. The polymer extrusion rate and winding speed were maintained in the ranges of and 50-100 g/min and $25-50 \mathrm{~m} / \mathrm{min}$ respectively and the outer surface of the extruded hollow fibre was also gelled in water bath. The spinning was also carried out from the spinning dope solution of PVDF $(15 \%, \mathrm{w} / \mathrm{w})$, PVP $(2 \%, \mathrm{w} / \mathrm{w})$ and DMF $(83 \%, \mathrm{w} / \mathrm{w})$. The fibres were rinsed in flowing water at room temperature for 72 hours.

Membrane morphologies were observed using optical microscopy (Olympus) and atomic force microscopy (NT-MDT). Zeta potentials of the membrane surfaces were measured by ZETA-CAD instrument using $10 \mathrm{mMol}$ aqueous $\mathrm{KCl}$ solution. Contact angle (water) of the membrane surface was measured according to sessile drop method using Krüss DSA 100E model. The overall porosity $(\varepsilon)$ of the PVDF hollow fiber was calculated by using following:

$$
\varepsilon=\left(1-\rho_{\text {fiber }} / \rho_{\mathrm{PVDF}}\right) \times 100 \%
$$

where $\rho_{\text {fiber }}$ and $\rho_{\text {PVDF }}$ are the densities of the fiber and the PVDF powder, respectively.

The polymer solute rejection (R, \%) was calculated using the following expression:

$$
\mathrm{R}=\left(1-\mathrm{C}_{\mathrm{P}} / \mathrm{C}_{\mathrm{F}}\right) \times 100
$$

where $\mathrm{C}_{\mathrm{F}}$ and $\mathrm{C}_{\mathrm{P}}$ are concentrations of solute in the feed and permeate, respectively. The solute concentrations were estimated using GPC (Analytical ${ }^{\circledR}$ Technologies Limited).

From flow permeability test, an equivalent pore size of membranes could be estimated. Assuming laminar flow, Hagen Poiseuille relationship can be derived into (Porter M.C., 1996):

$$
d=\sqrt{\frac{32 J \mu l}{\varepsilon \Delta P}}
$$

where $d$ is the average pore diameter $(\mathrm{m}), J$ is the volumetric liquid flow rate per unit area of membrane (m3.m-2), $l$ represents the length of pore (m), $\varepsilon$ is the membrane porosity (dimensionless) and $\Delta P$ is the differential pressure across the membrane $(\mathrm{Pa}), l$ is assumed to be the direct thickness of membrane with negligible tortuosity factor.

\subsection{Hollow fibre cartridges assembly and MD experiments}

Hollow fibre membrane cartridges with membrane area of $0.06 \mathrm{~m}^{2}$ were assembled for this study. To improve mass transfer in MD, specially designed baffles were inserted between fibres to improve the mass transfer and epoxy resin was used as the potting sealant for cartridge assembly. The module design modified by spacers/baffles/turbulence promoters has been found to increase both heat and mass-transfer coefficients via the 
generation of turbulence flow, changes in system characteristics that enhance boundary-layer heat and mass transfer, resulting in increased flux transfer (Teoh, et al., 2008).

Sweep gas MD experiments were carried out as shown schematically in Figure 1. The aqueous ammonia feed solution was pumped into the module from a feed tank by a Masterflex ${ }^{\circledR}$ peristaltic pump at a constant flow rate through the lumen side of the membrane. The inlet was heated to a desired temperature using a water bath before entering the module. The liquid outlet stream from the module was then recycled back to the feed tank. Compressed air at ambient temperature was introduced counter currently into the shell side of the membrane and the flow was controlled by using a mass flow controller. Permeate was collected via a condenser.

Figure 1. Experimental setup for hollow fibre membrane distillation.

Temperatures at streams (liquid and air) inlet and outlet were monitored using K-type thermocouples. The weight changes from both feed and permeate tanks were measured by digital balances and recorded in a computer attached to the system.

Ammonia removal calculations and ammonia analysis were described in detail elsewhere (Xie, et al., 2009).

The ammonia flux was calculated as follows:

$$
F_{N H_{3}}=\frac{\left(C_{i} * M_{i}-C_{e} * M_{e}\right)}{A^{*} t}
$$

Where $C_{i}$ and $C_{e}$ are concentrations $(\mathrm{mg} / \mathrm{L})$ of ammonia in the initial and final solution, respectively. $M_{i}$ and $M_{e}$ are amounts of liquid before and after the experiment, respectively. $A$ is the active membrane area $\left(\mathrm{m}^{2}\right)$ and $\mathrm{t}$ is the running time (hr).

\section{Results and Discussion}

\subsection{Membrane characterisation}

Three types of hollow fibre PVDF membranes were fabricated. Membranes 851 and 853 were fabricated from the same dope solution (PVDF 12\%, EG $8 \%$ and NMP $80 \%, \mathrm{w} / \mathrm{w}$ ) by varying extrusion and winding rate while the membrane 861 were fabricated from a different dope solution (PVDF $15 \%$, PVP 2\% and DMF 83\%, w/w). The characteristics of these membranes are presented in Table 1.

The membrane diameters and thicknesses varied from 1.16 to $1.35 \mathrm{~mm}$ and 0.28 to $0.40 \mathrm{~mm}$ respectively depending upon the spinning operational parameters such as polymer extrusion and fibre winding rate. Overall porosity varied from 81 to $88 \%$. The water permeabilities were in the range of $469-770 \mathrm{~L} \cdot \mathrm{m}^{-2} \cdot \mathrm{h}^{-1} \cdot \mathrm{bar}^{-1}$ with about $91-96 \%$ PEO $100 \mathrm{kDa}$ rejection efficiency. The membranes obtained from the polymer dope solution of PVDF-EG-NMP (851 and 853) had water contact angle of $\sim 100^{\circ} ; 7^{\circ}$ higher than that obtained from the PVDF-PVP-DMF dope (861), indicating relatively more hydrophobic surface. Membrane 853 had the biggest equivalent pore size $(0.17 \mu \mathrm{m})$, membranes 861 and 851 had pore sizes of $0.13 \mu \mathrm{m}$ and $0.11 \mu \mathrm{m}$ respectively.

Table 1. Membrane properties of PVDF hollow fibre membranes.

These membranes also differed in their cross-sectional microstructure morphology as shown in the optical microscope images (Figure 2). Compared to membranes obtained from PVDF-PVP-DMF dope solution (861), membranes from PVDF-EG-NMP dope (851 and 853) had larger voids and the cross-sectional microstructure remained unaltered upon changing the fibre dimensions through the extrusion/spinning rate. The different doping solutions also altered the zeta potential of membranes, as shown in Figure 3. The PVDF membrane from PVDF-EG-NMP dope (851) had negative zeta-potential values of -2.4 to -11.3 at the $3-9 \mathrm{pH}$ range while the membrane from PVDF-PVP-DMF dope (861) had slightly higher negative zeta potential. This implied that the membrane surface from PVDF-PVP-DMF dope had relatively higher charge which agrees well with the lower contact angle value (Table 1).

Figure 2. Cross-sectional optical microscope images of membranes 851,853 and 861.

Figure 4 shows the two- and three-dimensional AFM images of the two PVDF fiber types (sample 851 and 861) taken at two different magnifications of [20 $\mu \mathrm{m} \times 20 \mu \mathrm{m}]$ and [5 $\mu \mathrm{m} \times 5 \mu \mathrm{m}]$ frame sizes. The sample 851 surface had larger peaks of micrometer-scale heights $(0.5-1.5 \mu \mathrm{m})$ while the sample 861 surface had smaller domains of nanometer-scale peaks $(150-300 \mathrm{~nm})$ indicating that the sample 861 surface was relatively smoother.

Figure 3. Zeta-potential values of the two PVDF fiber types measured at the pH 3 -9. 
Figure 4. Two- and three-dimensional AFM images of 851 and 861 fiber surfaces at two different magnifications.

\subsection{Membrane performance}

Results for ammonia removal rate by PVDF membranes are shown in Figure 5; membrane 853 displayed the highest ammonia removal efficiency with up to $90 \%$ of ammonia being removed in the first 100 minutes. Membrane 861 had the lowest ammonia removal efficiency, at only $64 \%$. The higher ammonia removal rates obtained for membranes 851 and 853 could be attributed to the larger macrovoid structure obtained by using the doping solution PVDF-EG-NMP (Figure 2). The thin skin layer acted as the selective layer and the larger macrovoid aided the mass transfer of ammonia due to reduced mass transfer resistance. In addition, membrane 851 and 853 are more hydrophobic compared with membrane 861 , as depicted by the water contact angle differences (Table 1).

Figure 5. Ammonia removal rate of membranes.

It is well known that the membrane properties had significant effect on the performance of the MD process. The relationship between the transmembrane flux and the different membrane characteristic parameters is given as follows (Lawson, \& Lloyd, 1997):

$$
N=\frac{r^{a} \varepsilon}{\delta_{m} \tau}
$$

where $N$ is the molar flux, $r$ is the mean pore size of the membrane pores, a is the factor whose value equal to 1 or 2 for Knudsen diffusion and viscous fluxes, respectively, $\delta_{m}$ is the membrane thickness, $\varepsilon$ is the membrane porosity and $\tau$ is the membrane tortuosity.

Despite of the differences in thickness of the membranes (Table 1), membrane 853 which had an estimated pore size of $0.17 \mu \mathrm{m}$ performed better than membrane 851 with estimated pore size of $0.11 \mu \mathrm{m}$.

Membrane performance was also compared at different feed concentrations ranging from 100-1000 ppm, and the results for ammonia flux are shown in Figure 6. The trend in ammonia flux is quite similar for all three types of membranes. The ammonia flux increased with increasing feed concentration. Of three membranes, membrane 853 outperformed the other two under all feed concentration studied. An ammonia flux of $11.0 \mathrm{~g} . \mathrm{m}^{-2} \cdot \mathrm{h}^{-1}$ was achieved for membrane 853 at the initial ammonia concentration of $1000 \mathrm{ppm}$. It is worth noting that the differences in magnitude of ammonia flux variation among these membranes became bigger when the ammonia feed concentration was increased. This is due to the fact that ammonia flux was proportional to the initial feed concentrations. When the amount of liberated ammonia in the gas phase increased; partial vapour pressure is increased and the driving force for ammonia to diffuse through the membrane pores also became stronger, hence ammonia flux is increased.

Figure 6. Ammonia flux of three compared membranes at various initial feed concentrations.

Figure 7 shows the effect of feed concentration on the water flux. For all three types of membranes, the feed concentration had little or negligible effect on the water flux. This result was understandable as the major component in the solutions used in the study was water $(>99.9 \%)$. Little change in the ammonia concentrations had no affect in the mass transport of the water. Therefore, the water flux remained relatively constant. Comparing membranes fabricated under different conditions, membrane 853 had the highest water flux averaged at $2.4 \mathrm{~kg} \cdot \mathrm{m}^{-2} \cdot \mathrm{h}^{-1}$, followed by sample 861 and 851 with 2.2 and $2.0 \mathrm{~kg} \cdot \mathrm{m}^{-2} \cdot \mathrm{h}^{-1}$, respectively. This agrees well with the water permeability data as shown in Table 1 . The membrane 853 has highest water permeability which could be due to its relative large pore size (Table 1).

Figure 7. Water flux of three compared membranes at various initial feed concentrations.

\section{Conclusions}

Asymmetric PVDF hollow fibre membranes were synthesised and characterised in terms of porosity, thickness, hydrophobicity, water permeability, zeta potential and equivalent pore size. Doping solution was found to significantly affect the membrane microstructure and membrane properties, which consequently leads to different membrane performance. The membranes were assembled into MD cartridges with improved features for removing ammonia $(<1000 \mathrm{ppm})$ from aqueous solutions. Sweep gas MD configuration was applied and membrane fabricated using doping solution PVDF-EG_NMP had higher ammonia removal efficiency, with the ability to remove up to $90 \%$ of ammonia. Ammonia removal rates and water fluxes were independent of the ammonia feed concentrations. 


\section{References}

Bougeecha, S., Chouikh, R., \& Dhahbi, M. (2002). Numerical study of the coupled heat and mass transfer in membrane distillation. Desalination, 152. 245-252. http://dx.doi.org/10.1016/S0011-9164(02)01070-6

El-Bourawi, M. S, Ding, S., Ma, R., \& Khayetie, M. (2006). A framework for better understanding membrane distillation separation process. Journal of Membrane Science, 285. 4-29. http://dx.doi.org/10.1016/j.memsci.2006.08.002

Kong, J., \& Li, K. (2001). An improved gas permeation method for characterising and predicting the performance of microporous asymmetric hollow fibre membranes used in gas absorption. Journal of Membrane Science, 182. 271-281. http://dx.doi.org/10.1016/S0376-7388(00)00573-1

Lawson, K. W., \& Lloyd, D. R. (1997). Membrane distillation. Journal of Membrane Science, 124. 1-25. http://dx.doi.org/10.1016/S0376-7388(96)00236-0

Li, K., Kong, J., \& Tan, X. (2000). Design of hollow fibre membrane modules for soluble gas removal. Chemical Engineering Science, 55. 5579-5588. http://dx.doi.org/ 10.1016/S0009-2509(00)00193-7

Mulder, M. (1996). Basic Principles of Membrane Technology. $2^{\text {nd }}$ Edition, Kluwer Academic Publishers.

Porter, M. C. (1990). Handbook of Industrial Membrane Technology. Noyes Publications. 77-78.

Qin, Y., Cabral, J. M. S., \& Wang, S. (1996). Hollow-fiber gas-membrane process for removal of NH3 from solution of NH3 and CO2. AIChE Journal, 42. 1945-1956. http://dx.doi.org/10.1002/aic.690420715

Semmens, M. J., Foster, D. M., \& Cussler, E. L. (1990). Ammonia removal from water using microporous hollow fibers. Journal of Membrane Science, 51. 127-140. http://dx.doi.org/10.1016/S0376-7388(00)80897-2

Tan, X., Tan, S. P., Teo, W. K., \& Li, K. (2006). Polyvinylidene fluoride (PVDF) hollow fibre membranes for ammonia removal from water. Journal of Membrane Science, $271.59-68$. http://dx.doi.org/10.1016/j.memsci.2005.06.057

Teoh, M. M., Bonyadi, S., \& Chung, T. (2008). Investigation of different hollow fiber module designs for flux enhancement in the membrane distillation process. Journal of Membrane Science, 311. 371-379. http://dx.doi.org/10.1016/j.memsci.2007.12.054

Xie, Z., Duong, T., Hoang, M., Nguyen, C., \& Bolto, B. (2009). Ammonia removal by sweep gas membrane distillation. Water Research, 43. 1693-1699. http://dx.doi.org/ 10.1016/j.watres.2008.12.052

Zhu, Z., Hao, Z., Shen, Z., \& Chen, J. (2005). Modified modeling of the effect of pH and viscosity on the mass transfer in hydrophobic hollow fiber membrane contactors. Journal of Membrane Science, 250. 269-276. http://dx.doi.org/10.1016/j.memsci.2004.10.031

Table 1. Membrane properties of PVDF hollow fibre membranes

\begin{tabular}{lccc}
\hline Sample code & $\mathbf{8 5 1}$ & $\mathbf{8 5 3}$ & $\mathbf{8 6 1}$ \\
\hline Water contact angle $\left(^{\circ}\right)$ & 99 & 100 & 93 \\
Outer diameter $(\mathrm{mm})$ & 1.16 & 1.35 & 1.29 \\
Inner diameter $(\mathrm{mm})$ & 0.88 & 0.95 & 0.91 \\
Fibre wall $(\mathrm{mm})$ & 0.28 & 0.40 & 0.38 \\
Porosity $(\%)$ & 88 & 81 & 81 \\
Water permeability $\left(\mathrm{L}^{\mathrm{m}} \mathrm{m}^{-2} \cdot \mathrm{h}^{-1} \cdot \mathrm{bar}^{-1}\right)$ & 469 & 770 & 476 \\
Rejection $(\%)(\mathrm{PEO} 100 \mathrm{kDa})$ & 96 & 91 & 91 \\
Estimated pore size $(\mu \mathrm{m})$ & 0.11 & 0.17 & 0.13 \\
\hline
\end{tabular}




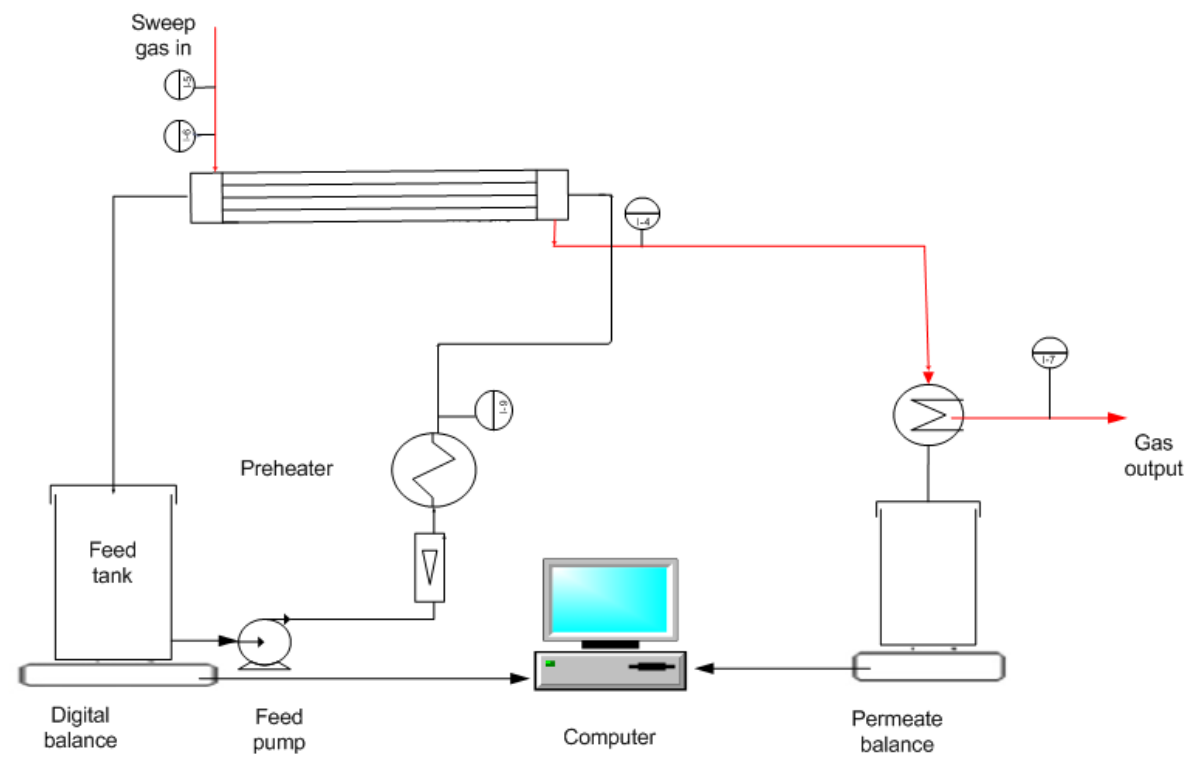

Figure 1. Experimental setup for hollow fibre membrane distillation

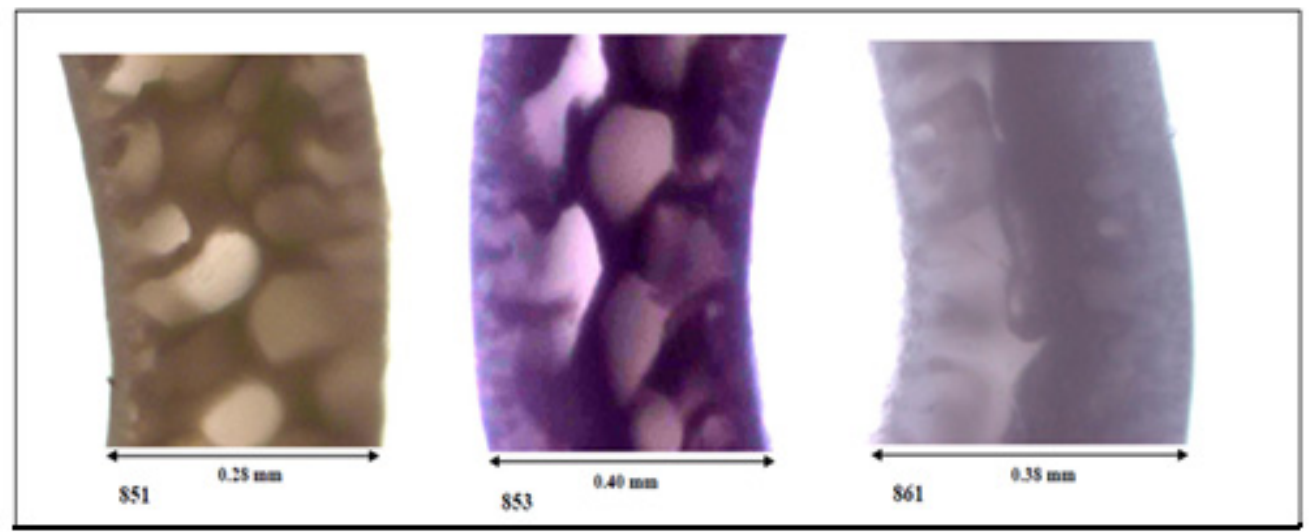

Figure 2. Cross-sectional optical microscope images of membranes 851, 853 and 861 


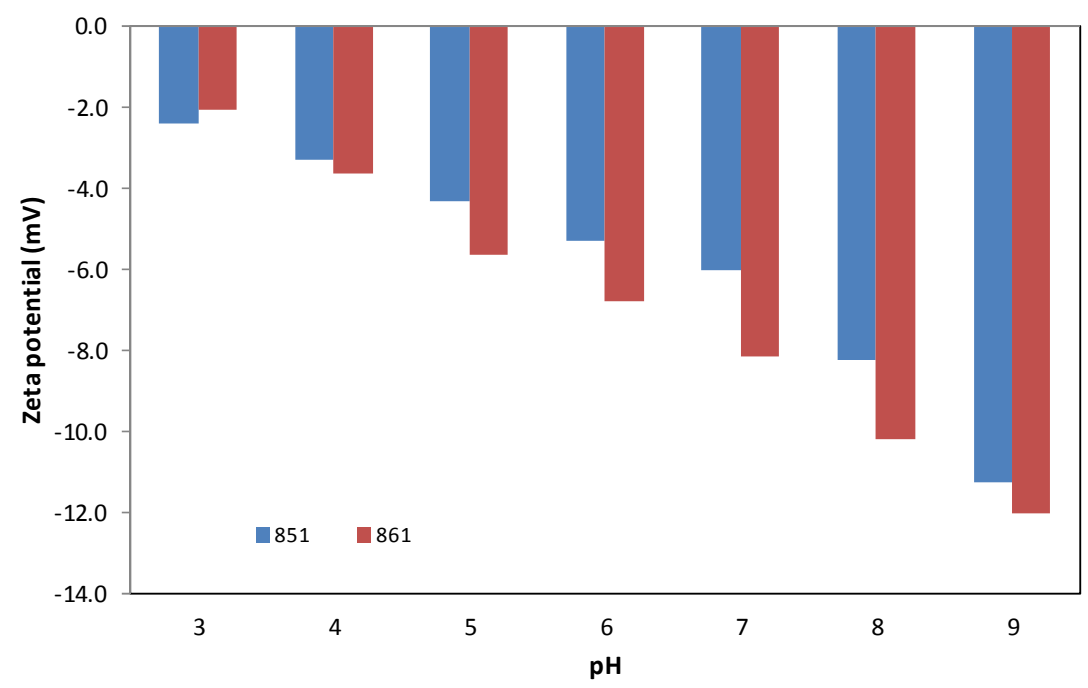

Figure 3. Zeta-potential values of the two PVDF fiber types measured at the $\mathrm{pH} 3$-9
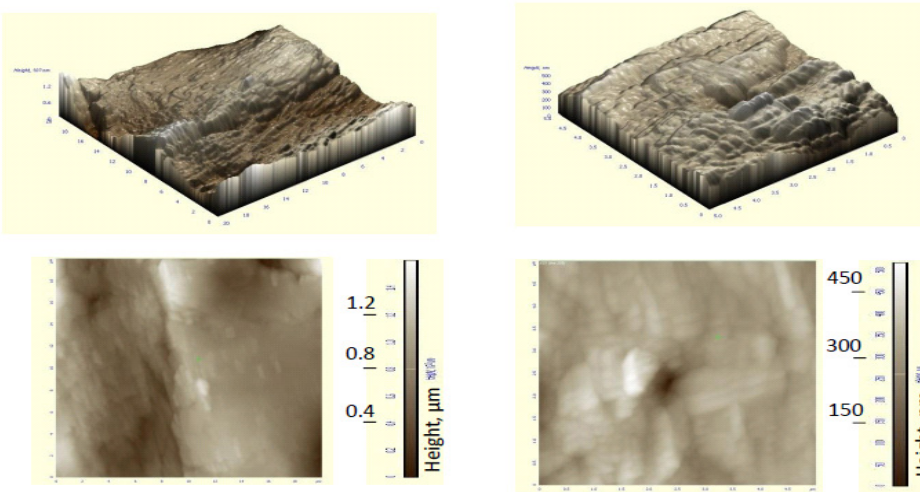

2 and $3 D$ images $(20 \mu \mathrm{m} \times 20 \mu \mathrm{m})$

SAMPLE 851
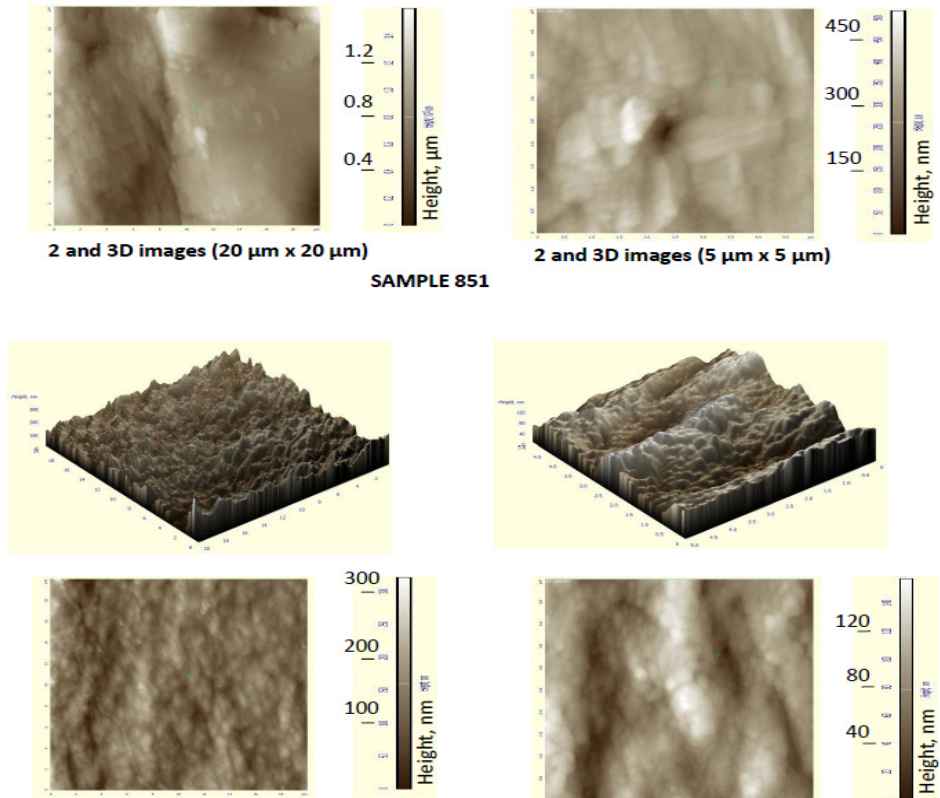

2 and 3D images $(20 \mu \mathrm{m} \times 20 \mu \mathrm{m})$ SAMPLE 861

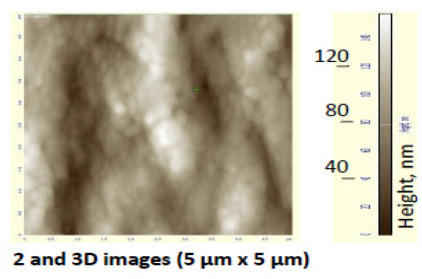

Figure 4. Two- and three-dimensional AFM images of 851 and 861 fiber surfaces at two different magnifications 


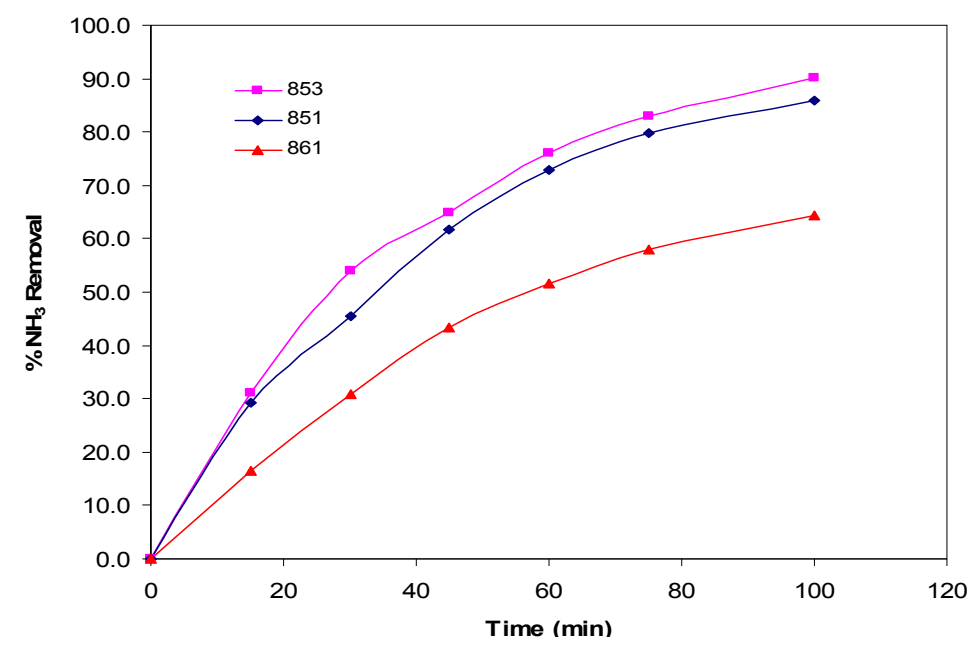

Figure 5. Ammonia removal rate of membranes

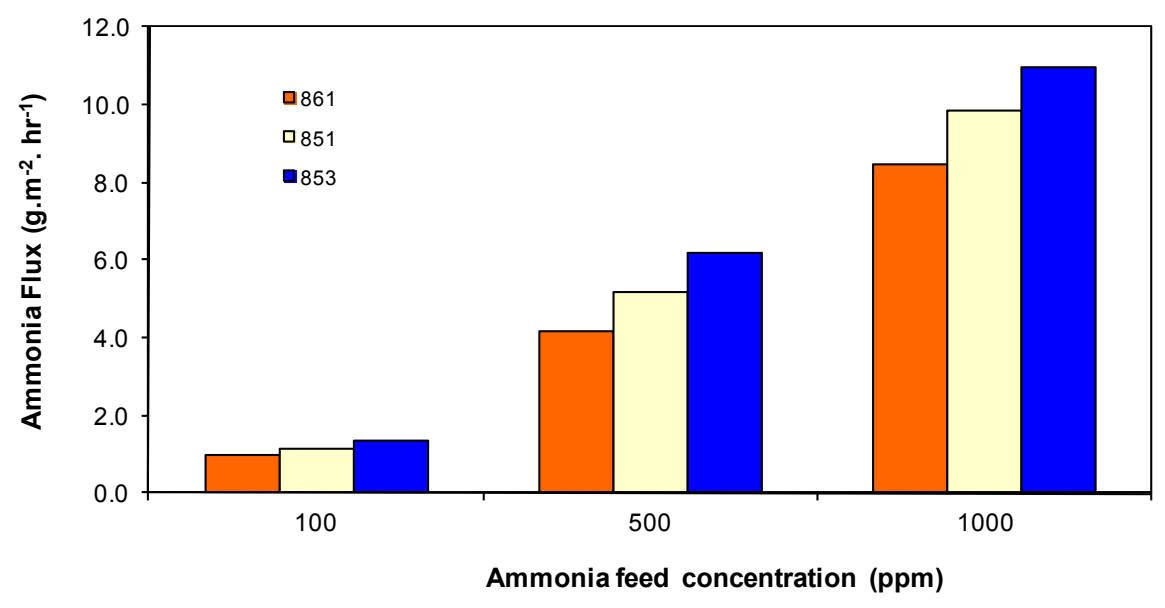

Figure 6. Ammonia flux of three compared membranes at various initial feed concentrations

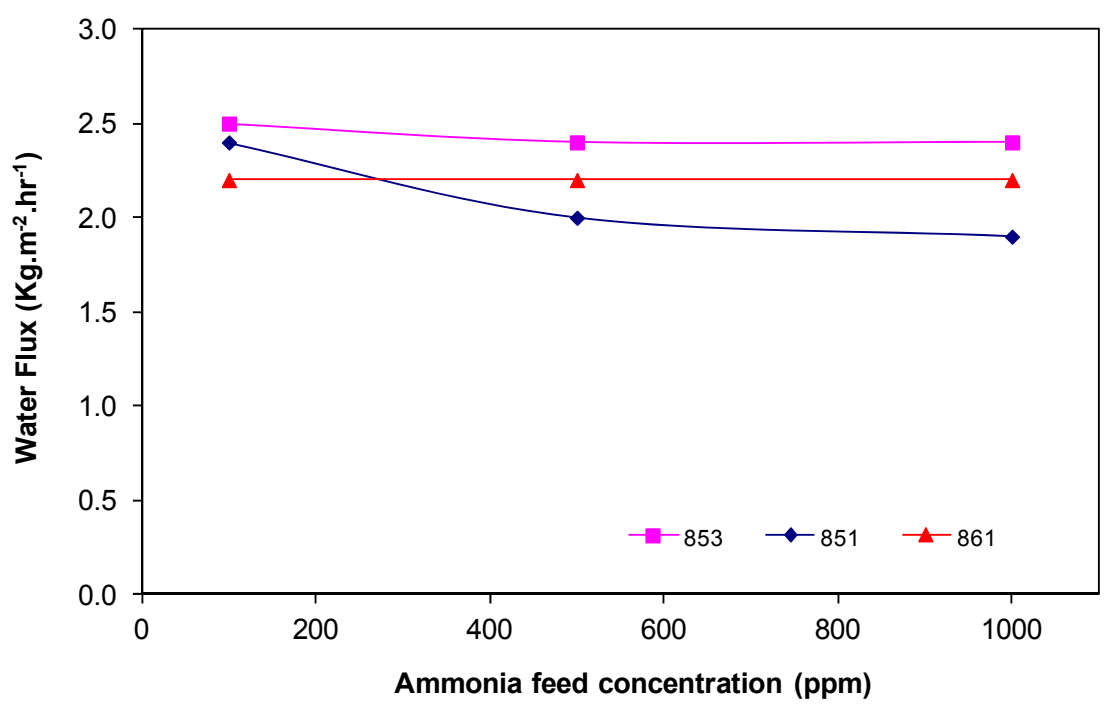

Figure 7. Water flux of three compared membranes at various initial feed concentrations 